NBER WORKING PAPER SERIES

\title{
OIVERGENT EXPECTATIONS AS A CAUSE \\ OF DISAGREEMENT IN BARGAINING: \\ EVIOENCE FROM A COMPARISON \\ OF ARBITRATION SCHEMES
}

Max H. Bazerman

Henry S. Farber

Working Paper No. 2139

NATIONAL BUREAU OF ECONOMIC RESEARCH 1050 Massachusetts Avenue

Cambridge, MA 02138

January 1987

The authors thank Bob Gibbons for very useful comments on an earlier draft of this paper. Useful feedback was also received from participants in a workshop at Cornell University. The research reported here is part of the NBER's research program in Labor Studies. Any opinions expressed are those of the authors and not those of the National Bureau of Economic Research. 
NBER Working Paper \#2139

January 1987

Divergent Expectations as a Cause of Disagreement in Bargaining: Evidence From a Comparison of Arbitration Schemes

\begin{abstract}
$\underline{\text { ABSTRACT }}$
One prominent explanation for disagreement in bargaining is that the parties have divergent and relatively optimistic expectations regarding the ultimate outcome if they fail to agree. The fact that settlement rates are much higher where final-offer arbitration is the dispute settlement procedure than where conventional arbitration is the dispute settlement procedure is used as the basis of a test of the role of divergent expectations in causing disagreement in negotiations. Calculations of identical-expectations contract zones using existing estimates of models of arbitrator behavior yield larger identical-expectations contract zones in conventional arbitration than in final-offer arbitration. This evidence clearly suggests that divergent expectations alone are not an adequate explanation of disagreement in labormanagement negotiations. A number of alternative explanations for disagreement are suggested and evaluated.
\end{abstract}

Max H. Bazerman

Kellogg Graduate school of Management Northwestern University 2001 Sheridan Road Evanston, IL 60201
Henry S. Farber Department of Economics MIT

Building E52-252F

Cambridge, MA 02139 
I. Introduction

One of the enduring puzzles in the analysis of bargaining is why there is ever disagreement in cases where agreement appears to be in the interests of both parties. For example, in labor-management negotiations, disagreement imposes costs (of arbitration or of a strike) on both parties without increasing the resources available to be split by the two parties. Failures of negotiation lead to costly strikes, decreased harmony in the workplace, and threats to the survival of the organization and the jobs of organizational members. The labor-management relationship is just one case in which inefficiencies appear inherent in the negotiation process. Other important inefficiencies occur in international negotiations over trade and political issues, merger negotiations, and family disputes (Raiffa, 1982; Pruitt and Rubin, 1985; Lewicki, Sheppard, and Bazerman, 1986).

One prominent explanation for disagreement in bargaining is that the parties have divergent and relatively optimistic expectations regarding the ultimate outcome if they fail to agree (Hicks, 1963; Farber and Katz, 1979; Bazerman and Neale, 1982). In the case where a third party will render a decision if the parties fail to agree, both parties expect to receive a relatively favorable decision from the third party. In final-offer arbitration, where the arbitrator must accept one offer or the other (and not compromise), it is obvious that $50 \%$ of the final offers submitted ( 1 of 2 ) will be accepted. Neale and Bazerman (1983) found strong evidence of relatively optimistic expectations when they asked subjects in a bargaining experiment the probability that their final offer would be accepted. The average probability estimate was fully $68 \%$. Such relative optimism can prevent sufficient concessions in the negotiation process as both parties inappropriately expect a favorable disagreement outcome.

There is substantial evidence supporting the claim that divergent 
expectations are common, and that they can be a cause of disagreement in bargaining. However, the magnitude of the effect of divergent expectations on the likelihood of disagreement is in question. In this study, we examine two alternative forms of arbitration: conventional and final-offer. It is well known that negotiated settlement rates are much higher under final-offer arbitration than under conventional arbitration (e.g., Feuille, 1975; Kochan and Baderschneider, 1978; Notz and Starke, 1978; Grigsby and Bigoness, 1982; Neale and Bazerman, 1983). We develop the argument that the hypothesis that divergent expectations are the primary cause of disagreement implies that contract zones computed assuming (perhaps counterfactual) identical expectations will be larger under the form of arbitration that leads to the higher settlement rate. We then examine empirical evidence on settlement rates under the different forms of arbitration and compare them to the predicted identical-expectations contract zones in order to explore whether or not the data are consistent with the divergent expectations prediction. Finally, we explore other explanations of disagreement in order to account for the many important negotiation failures that occur in various settings.

Arbitration procedures are used in most U.S. labor contracts to settle disputes that arise in the course of administration of labor agreements. This is termed grievance arbitration. ${ }^{1}$ In order to avoid strikes by public sector employees, by 1981 twenty states had specified that arbitration is to be used to determine the actual terms of labor contracts among public sector employees where the parties cannot agree (Freeman, 1986). This is termed interest arbitration, and it is the focus of the analysis here.

Two types of arbitration are in wide use to settle interest disputes in

1. In 1980, approximately 97 percent of collective bargaining agreements in the private sector covering 1000 or more workers included grievance procedures with arbitration. (U.S. Bureau of Labor Statistics, 1981). 
tine public sector. Conventional arbirration $(C A)$, where the arbitratcr is free to make any award he or she sees fit, was the first to be used. After some experience with this form of arbitration in the public sector, it was argued that the arbitrator will have an incentive to split the difference between the last offers of the parties resulting in a "chilling" of bargaining as each party maintains extreme positions in order to receive a favorable arbitration award in the event the parties fail to reach a negotiated settlement. Final-offer arbitration (FOA), where the arbitrator is constrained to make an award that is equal to one or the other of the parties' last offers, is argued not to chill bargaining because the arbitrator is explicitly prohibited from splitting the difference. In 1981 ten states had laws specifying $C A$ and ten states had laws specifying FOA to settle interest disputes with some or all public employees (Freeman, 1986).

While the empirical evidence seems clear that settlement rates are, in fact, higher under FOA, the rationale outlined above is not adequate. Implicitly, this rationale relies on the assumption that contract zones (the range of settlements that both parties would prefer to disagreement) are larger or more likely to exist under FOA. However, this assumption is not necessarily accurate. First, it is an empirical matter as to whether or not contract zones are larger or more likely to exist in FOA (Farber 1980b), and there is no direct evidence on this issue. Second, without a theory of disagreement it is not clear that larger contract zones, do in fact lead to more settlements. In the next section a theory of disagreement as being the result of relatively optimistic expectations regarding the disagreement outcome is briefly outlined. This model has the clear implication that larger identical-expectations contract zones lead to more agreement. Accepting the empirical evidence that there is higher likelihood of settlement in FOA than in CA, a natural test of the theories, based on a comparison of the relative 
sizes of the contract zones in the two types of arbitration, is proposed. Section III contains a brief description of the model of the parties' decisions regarding their optimal offers given their expectations regarding arbitrator behavior. These models are then used to describe how the implied contract zones are derived under the two types of arbitration.

Given that the contract zone in arbitration depends fundamentally on the behavior of the arbitrator, section IV contains a description of arbitrator behavior in CA based on the model developed and estimated by Farber and Bazerman (1986). Similarly, section V contains a description of arbitrator behavior in FOA based on the same underlying model. Empirical estimates of the parameters of the model of arbitrator behavior serve as an important component of the calculation of contract zone sizes.

In section VI the particular pieces of the model required to compute contract zone sizes, the preferences of the parties over the range of possible outcomes and their prior distribution on the behavior of the arbitrator, are specified. The computation of the contract zones based on these components is also described.

In section VII the actual computations of contract zones are presented for a range of risk preferences of the parties, uncertainty regarding the arbitrator's behavior, and arbitrator sensitivity to the offers in CA. The clear finding is that contract zones are substantially larger in CA than in FOA. This finding is not consistent with the divergent expectations model of disagreement.

Section VIII contains a discussion of four alternative explanations of disagreement in view of the limitations of the divergent expectations explanation found in the analysis. Each of these theories is evaluated and discussed with regard to their implications for the empirical evidence presented in this paper. 
II. Divergent Expectations, the Contract Zone, and Disagreement

A dispute settlement procedure will provide an incentive for the parties to reach a negotiated agreement to the extent that the procedure imposes costs on the parties in the event they fail to agree. Farber and Katz (1979) argue that arbitration imposes costs on the parties largely due to the combination of risk aversion by the parties and their uncertainty regarding the behavior of the arbitrator. To the extent that the parties are risk averse, they will be willing to concede in negotiation from the expected arbitration award in order to avoid the risk of an unfavorable award. Assuming that the parties have identical expectations about the uncertain arbitration award, the result is a contract zone of settlements that both parties prefer to disagreement. In what follows this is called the identical-expectations contract zone to distinguish it from the contract zone, per se, which is the range of settlements (if any) that both parties prefer to disagreement in practice, where expectations regarding the arbitration award may differ.

The simplest theory of disagreement in this context is based on the possibility that the parties have different prior distributions on the arbitration award. If the parties are relatively optimistic regarding the likely arbitration award (e.g., the union expects a higher wage award than the employer expects) then the union will be willing to concede downward from a higher wage than the employer is will to concede upward from. As noted in the introduction, there is empirical evidence in the behavioral science literature on negotiation suggesting that negotiators, and decision makers in general, are overconfident and overoptimistic in their uncertain judgments (Neale and Bazerman, 1983; Bazerman and Neale, 1982). Thus, while relative optimism is not consistent with a simple equilibrium economic model, it may well be true that negotiators systematically misperceive their environment in ways that 
could iead to cisagreement.

Unless the costs imposed by uncertainty are sufficient to offset these divergent expectations completely, there will not be a contract zone and there will be no agreement. The identical-expectations contract zone, because it is an indicator of the costs imposed by the uncertainty regarding the arbitration award, is a direct measure of how robust the actual contract zone is to differences in expectations. Assuming that systematic differences in expectations are independent of the type of arbitration scheme, this divergent expectations model has the clear implication that larger identicalexpectations contract zones will lead to a higher likelihood of agreement in actual cases where expectations may well differ.

In order to see this more clearly, consider a very simple model where a union and employer are bargaining over some value $Y$ where the union's utility is positively related to $Y$ and the employer's utility is negatively related to Y. For example, Y might represent the wage. Let the cost of disagreement to the union and employer respectively be represented by $C_{u}$ and $c_{m}$ respectively. Let the union's and management's expectations regarding the arbitration award be $Y_{a u}$ and $Y_{a m}$ respectively. Where the union and employer are risk-neutral $\left(V_{u}(Y)=Y\right.$ and $\left.V_{m}(Y)=-Y\right)$, the union will be willing to accept any settlement, $Y_{n u^{\prime}}$ such that

$$
\text { (2.1) } Y_{n u} \geq Y_{a u}-C_{u^{\prime}}
$$

and the management will be willing to accept any settlement such that

$$
\text { (2.2) } \mathrm{Y}_{\mathrm{nm}} \leq \mathrm{Y}_{\mathrm{am}}+\mathrm{C}_{\mathrm{m}} \text {. }
$$

The contract zone is defined by

$$
\text { (2.3) } C Z=Y_{n m}-Y_{n u}=\left(Y_{a m}-Y_{a u}\right)+\left(C_{u}+C_{m}\right) \text {. }
$$

Where expectations are identical, $Y_{a m}=Y_{a u}$ and the identical-expectations contract zone reduces to the sum of the costs of disagreements,

$$
\text { (2.4) } \quad C z_{0}=C_{u}+C_{m} \text {. }
$$


Thus, the contiant zone in general is

(2.5) $\mathrm{CZ}=\mathrm{CZ}_{0}+\left(\mathrm{Y}_{\mathrm{am}}-\mathrm{Y}_{\mathrm{au}}\right)^{\prime}$,

and a contract zone is more likely to exist for a given degree of difference in expectations where $\mathrm{CZ}_{0}$, the contract zone in the case of identical expectations, is larger.

From the discussion in this section, the divergent expectations theory of disagreement can be examined based on a comparison of identicalexpectations contract zones under CA versus FOA. Assume first that the evidence that FOA leads to less disagreement than $C A$ is accurate. Next, compute the contract zones implied by $C A$ and FOA. If it is found that contract zones are larger in FOA than in $C A$, then the divergent expectations theory has additional support. However, evidence that contract zones are larger in $C A$ would not be consistent with the divergent expectations model, and alternatives would need to be considered. It must be noted that we are not testing whether or not divergent expectations exist or whether divergent can be a cause of disagreement. Both of these questions have been answered affirmatively by theoretical and empirical analysis in the existing literature. Rather, this paper examines the sufficiency of the divergent expectations theory in accounting for disagreement in labor-management negotiations.

\section{Negotiator Behavior}

A key feature of arbitrator behavior from the standpoint of the negotiators is that they are likely to be uncertain about the arbitration award, $Y_{S}$, in a particular case. More formally, the arbitration award can be expressed as

$$
\text { (3.1) } Y_{s}=h_{i}\left(Y_{e}, Y_{u}, Y_{m}\right)
$$

where $Y_{e}$ represents the arbitrator's notion of an appropriate award 
independent of the offers, $Y_{u}$ is the union's offer, and $Y_{m}$ is the management's offer. The function $h_{i}(\cdot)$ represents the arbitration process by which $Y_{e}$ and the offers are combined to determine the award, and $i=c, f$ indexes the type of arbitration scheme (conventional and final-offer respectively). ${ }^{2}$ The likely source of the uncertainty is that the parties do not know $Y_{e}$.

Each party, given its prior expectations and an assumption about its opponents prior expectations, can compute the Nash equilibrium offers associated with the type of arbitration that is in use. Where expectations are identical, it is natural that each party derives the Nash equilibrium assuming it's opponent's expectations are the same as its own. Where expectations, in fact, differ each party may still proceed as if their opponent has the same expectations it does. However, at some point it will become apparent that the opponent actually holds different expectations. More realistically, the difference in expectations may be common knowledge (an "honest" difference of opinion?) so that each party computes the Nash equilibrium offers with its own expectations about $y_{e}$ but incorporating the fact that their opponent is proceeding with their own expectations. The basic conclusions of the analysis are not sensitive to which of these assumptions are used, and the analysis proceeds assuming that the parties have identical expectations about $\mathrm{y}_{\mathrm{e}}$.

From the Nash equilibrium offers each party can compute its equilibrium expected utility from arbitration. Economic rationality requires that the party not accept any negotiated settlement that yields it a utility level lower than the expected utility from arbitration. More formally, let the union's utility function be defined as

2. Clearly, the $h(\cdot)$ function will be different in the two forms of arbitration, and the succeeding two sections of the paper focus on the form of 


$$
\text { (3.2) } \mathrm{U}_{\mathrm{u}}=\mathrm{U}_{\mathrm{u}}(\mathrm{y})
$$

where $U_{u}{ }^{\prime}>0$, and let the employer's utility function be defined as

$$
\text { (3.3) } U_{m}=U_{m}(Y)
$$

where $\mathrm{U}_{\mathrm{m}}$ ' 10 .

Assume that the parties' identical prior distribution regarding $\mathrm{Y}_{\mathrm{e}}$ is characterized by the density function $g(\theta)$ where $\theta$ is a parameter vector. ${ }^{3}$ on this basis, the union's expected utility from arbitration is

$$
\text { (3.4) } E\left[U_{u}\right]=E\left[U_{u}\left\langle h_{i}\left(Y_{e}, Y_{u}, Y_{m}\right)\right)\right]
$$

where the expectation is taken over $\mathrm{Y}_{\mathrm{e}}$. Similarly, the employer's expected utility from arbitration is

(3.5) $E\left[U_{m}\right]=E\left[U_{m}\left(h_{i}\left(Y_{e}, Y_{u}, Y_{m}\right)\right)\right]$.

Note that the form of these general expressions are independent of whether $C A$ or FOA is in use. The form of the expectation and the role of the prior distribution function $(g(\theta))$ depend crucially on the type of arbitration, but in both cases the expected utilities are functions of both offers and the parameters of the prior distribution on $\mathrm{Y}_{e} \cdot 4$ Differentiating these expected utilities with respect to $Y_{u}$ and $Y_{m}$ respectively and setting the results equal to zero yields two equations in two unknowns (the offers) that can be solved for the Nash equilibrium final offers. Denote the expected utilities evaluated at the equilibrium offers by $E^{*}\left[U_{U}\right]$ and $E^{*}\left[U_{m}\right]$. They are functions strictly of the parameters of both parties' utility functions and the parameters of the prior distribution on $\mathrm{Y}_{e}(\theta)$.

Each party can calculate the negotiated settlement $\left(Y_{c j}\right)$ that makes it

the $h(\cdot)$ function in $C A$ and FOA respectively.

3. This parameter vector contains all of the relevant facts of the case exclusive of the offers.

4. The detailed presentations of these functions in the conventional and final-offer cases are contained in Farber (1981) and Farber (1980a)

respectively. 
indifferent between a negotiated settlement and utilizing arbitration by equating $E^{\star}\left[U_{j}\right]=U_{j}\left(Y_{c j}\right)$ where $j=u, m$. The values $Y_{c u}$ and $Y_{c m}$ are the certainty equivalent settlements of each party and they bound potential negotiated settlements. The only negotiated settlements $\left(Y_{n}\right)$ that both parties will prefer to arbitration are those that satisfy

$$
\text { (3.6) } Y_{\mathrm{cu}}<Y_{\mathrm{n}}<\mathrm{Y}_{\mathrm{cm}} \text { ' }
$$

and the range from $Y_{\mathrm{cm}}-Y_{\mathrm{cu}}$ defines the contract zone. As long as $Y_{\mathrm{cm}}$ is larger than $Y_{c u}$ there will exist mutually agreeable settlements and the simplest theories of bargaining imply that there will be a negotiated settlement.

It can be shown that a sufficient condition for there to be a positive contract zone for the model outlined here is that neither party be risk seeking. This is independent of whether $C A$ or FOA is used. Thus, it seems as if the parties always ought to reach negotiated agreements under both types of arbitration. Of course, this is not the case, and the model must be incomplete in a fundamental way. One obvious problem with the model is that the assumption was made that both parties had the same prior distribution $(g(\theta))$ regarding the arbitrator's notion of an appropriate award $\left(Y_{e}\right)$. If the parties have different expectations about $Y_{e}$ (i.e., different $\theta^{\prime} s$ ) then their optimal offers and certainty equivalents will differ from the ideal derived above. More to the point, if the parties have relatively optimistic expectations about $Y_{e}$ (for example, the mean of the union's prior distribution on $Y_{e}$ is higher than the employer's) then $Y_{c u}$ will be higher relative to $Y_{c m}$ and the contract zone will be smaller than that derived above. ${ }^{5}$ If

5. This conclusion also follows under the alternative assumptions that the Nash equilibrium is derived 1) with each party assuming that its opponent has the same expectations its does even when this is inappropriate or 2) with each party understanding that its opponent has different expectations about the arbitrator. See the discussion of this issue earlier in this section. 
expectations are sufficiertly optimistic, the contract zone may even be negative. In this case there will be no mutually acceptable negotiated settlements, and the parties will resort to arbitration.

For the purposes of the discussion here assume that the extent of mismatch or relative optimism regarding $Y_{e}$ is independent of the type of arbitration scheme. In this context it is possible to restate the claim that FOA encourages more negotiated settlements than CA in the terms of the our model. The claim is that for a given amount of relative optimism regarding $Y_{e}$ (a given difference between $\theta_{u}$ and $\theta_{m}$ ) there is more likely to be a contract zone in FOA than in CA. It is a reasonable that movements in the means of the prior distributions have an effect in the same direction on the certainly equivalents. In other words, an increase in the union's prior expectation (holding the employer's fixed) yields an increase in the union's certainty equivalent settlement. The result is a decrease in the size of the contract zone. On this basis, the claim for FOA can be restated as declaring that the identical-expectations contract zone induced by FOA will be larger than the identical-expectations contract zone induced by $C A$. Intuitively, if the identical-expectation contract zone in FOA is larger it will take a greater degree of relative optimism in expectations to offset it completely. We turn now to descriptions of arbitrator behavior in the two types of arbitration required to calculate the relative size of the contract zones.

\section{Arbitrator Behavior in Conventional Arbitration}

Farber (1981) argues that the pure split-the-difference model of arbitrator behavior in $C A$, where the arbitration award is simply an average of the last offers, is not reasonable because it provides the parties with the incentive to make their offers infinitely extreme. This is certainly not consistent with observed behavior, and casual conversation with arbitrators 
suggests that this is because "unreasonable" offers are discounted or disregarded by arbitrators. Clearly, there must exist a standard against which to judge offers if some offers are to be thought unreasonable. Thus, a richer framework for understanding arbitrator behavior in CA is required. A reasonable framework is that the arbitrator examines the facts lexclusive of the offers) in a particular case and makes a judgment based solely on these facts regarding an equitable award. The actual award is then formulated as a weighted average of this equitable award and the average of the last offers of parties where the weights depend on the "quality" of the offers (Farber, 1981; Bazerman and Farber, 1985). More formally, the arbitration award $\left(Y_{S}\right)$ is

$$
\text { (4.1) } Y_{S}=\gamma Y_{e}+(1-\gamma) \bar{Y}
$$

where $Y_{e}$ is the arbitrator's idea of an appropriate award based strictly on the facts, $\bar{Y}$ represents the mean of the parties' last offers, and $\gamma$ is the weight on the appropriate award relative to the last offers. This is the framework underlying much of the recent empirical analyses of arbitrator behavior. Some empirical studies (Bloom, 1986) have proceeded under the assumption that $\gamma$ is fixed while others (Bazerman and Farber, 1985; Farber and Bazerman, 1986) have argued that $\gamma$ is a function of the quality of the offers. Specifically, they argue that $\gamma$ is an increasing function of the difference between the last offers.

If it is assumed that the weight on the offers $(1-\gamma)$ is fixed then the problem of unboundedness of the last offers remains. Imagine that the first party is interested in maximizing $Y_{\mathbf{S}}$ and the second party is interested in minimizing $Y_{S}$. Clearly, the first party can increase $Y_{s}$ without limit by increasing its offer which increases $\bar{Y}$, and the second party can decrease $Y_{S}$ without limit by decreasing its offer which decreases $\bar{Y}$.

Farber (1981) considers the case where $\gamma$ is sensitive to the quality of the offers and where the parties are uncertain about $Y_{e}$. In this situation, 
each side is faed to select its iut cef utility from an arbitration award. The Nash equilibrium pair of offers is derived, and it is demonstrated that the last offers are bounded. Interestingly, it is also shown that what appears to be splitting-thedifference behavior by the arbitrators (arbitration awards that can be described as weighted averages of the offers) may well be the parties choosing offers that "surround" the expectation of the arbitrator's appropriate award. To the extent that this is the correct model of arbitrator behavior, the degree of chilling of bargaining in $C A$ depends on the marginal effect of changes in the offers on the arbitration award, and it can only be resolved empirically.

The key studies that provide estimates of $\gamma$ are Bazerman (1985), Bazerman and Farber (1985), Bloom (1986), and Farber and Bazerman (1986). Bazerman and Farber use data derived from decisions of professional arbitrators in twenty-five rather tersely described hypothetical cases that were constructed so that the offers were orthogonal to the facts. They find both that the primary weight is on the facts of each case even where the offers are of relatively high quality (close together) and that the weight on the offers declines as the offers move further apart. Bloom uses data derived from the decisions of professional arbitrators in hypothetical cases that were patterned very closely after actual cases involving public sector employees in New Jersey. The arbitrators were presented with a complete record of facts of these cases while the offers were modified in each case when presented to different arbitrators in order to provide a range of offers corresponding to a given set of facts. There was no attempt to make the offers orthogonal to the facts. Bloom finds that the primary weight is on the offers so that, while the facts can have a substantial effect on the arbitration award indirectly through their effect on the offers, splitting-the-difference is quite a good 
description of arbitrator behavior in $C A$.

What accounts for the seeming difference between the findings of these studies? In our opinion it is largely a matter of interpretation. The apparent difference occurs because of the orthogonality of the facts and offers in Bazerman and Farber's study as opposed to the correlation of the facts and the offers in Bloom's study. What Bloom defines as the effect of the offers is, as he recognizes, some combination of the pure effect of the offers and the effect of that part of the offers that simply reflects the facts of the case.

In order to see this more clearly, consider the model of arbitrator behavior described above with fixed $\gamma$. Bloom essentially regresses the arbitration award on the average offer and a set of variable summarizing the facts. This regression model is

$$
\text { (4.2) } Y_{S}=\theta_{0}+\theta_{1} Y_{e}+\theta_{2} \bar{Y}+\varepsilon
$$

where $\theta_{1}$ and $\theta_{2}$ are the weights on the facts $\left(Y_{e}\right)$ and the offers $(\bar{Y})$ respectively, and $\varepsilon$ is a random component. ${ }^{6}$ However, the average offer can be thought of as a linear combination of the facts and a random component so that

$$
\text { (4.3) } \bar{Y}=\phi_{0}+\phi_{1} Y_{e}+\mu
$$

where $\Phi_{0}$ and $\Phi_{1}$ are parameters and $\mu$ is a random component. Substitution of equation (4.3) into equation (4.2) yields the "reduced form"

$$
\text { (4.4) } Y_{s}=\left[\theta_{0}+\theta_{2} \phi_{0}\right]+\left[\theta_{1}+\theta_{2}{ }_{1}\right] Y_{e}+\left[\varepsilon+\theta_{2}^{\mu]}\right. \text {. }
$$

It is clear from this expression that the overall effect of the facts on the arbitration award is $\left[\theta_{1}+\theta_{2} \phi_{1}\right]$ rather than simply $\theta_{1}$. Bloom's conclusion that splitting-the-difference is a good description of the behavior of arbitrators in $C A$ is based on the lack of significance of the estimate of $\theta_{1}$ when equation

6. This equation is the empirical analogue of equation (4.1) with fixed $r$. 
(4.2) is estimated. Fowever, it negiects the irdirect effect of $Y_{e}$ through the offers on the award. 7

Bloom's findings are properly interpreted as implying that the facts alone are not sufficient to explain arbitrator behavior in CA $\left(\theta_{2}>0\right)$, but it is impossible to determine exactly how important the offers are without an estimate of how the facts affect the offers $\left(\phi_{1}\right)$. Of course, in actual cases the offers are not often at odds with facts. Farber's (1981) model suggests that the offers largely reflect the facts of a particular case so that the observed offers will not be orthogonal to the observed facts. Bazerman and Farber's experiment of generating arbitration awards where the offers are orthogonal to the facts $\left(\phi_{1}=0\right)$ provides a clearer measure of the relative importance of the offers and the facts in influencing arbitration awards.

\section{Arbitrator Behavior in Final-offer Arbitration}

The behavior of the arbitrator is much clearer in FOA than in CA due to the restricted nature of the arbitrators behavior in the final-offer case. There is no debate regarding whether or the extent to which the arbitrator use the offers in making an award. The rules of FOA require use of the offers. Similarly, there is consensus that the arbitrator uses the facts in selecting that "winning" final offer. After all, what else could the arbitrator use to make a reasoned choice? ${ }^{8}$ This section is relatively brief, reflecting the general agreement regarding arbitrator behavior under FOA rather than any lack of understanding or interest in FOA relative to CA.

7. No evidence on the magnitude of $\phi$ is presented, but it is clearly positive from Bloom's description of the ${ }^{1}$ way in which the scenarios were developed.

8. As will be discussed in the last section of this paper, this transparency of arbitrator behavior may be part of the explanation for fewer disagreements under FOA. 
Farber (1980a) argues that where the arbitrator is constrained to select one or the other of the last offers as the arbitration award he/she will select the offer that is closest to the arbitrator's notion of an appropriate award $\left(Y_{e}\right)$. In this case, the probability of choosing the firm's offer is $\operatorname{Pr}\left(Y_{e}(\bar{Y})\right.$, and each party selects the offer that maximizes its expected utility. The tradeoff for the union is that a higher offer is worth more if it is selected but it has a lower probability of being selected. The firm faces an analogous tradeoff. Farber (1980a) derives the Nash equilibrium pair of offers in the FOA case. Given the tradeoff inherent in the final-offer process, the offers are bounded and there is no obvious chilling effect. This combined with the aforementioned ambiguity regarding arbitrator behavior in $\mathrm{CA}$ is the basis of the conventional wisdom that the availability of FOA is more likely to result in a negotiated settlement than $C A .9$

Ashenfelter and Bloom (1984) and Farber and Bazerman (1986) present evidence that is consistent with this model. Ashenfelter and Bloom, using data on actual police and fire arbitrations in New Jersey, find that the probability of selecting the employer's offer is directly related to the average final offer. In addition, they find that the determinants of $Y_{e}$ implicit in FOA awards are not significantly different from the determinants of $Y_{e}$ implicit in the $C A$ awards. Farber and Bazerman, using data generated from the same set of hypothetical cases decided by professional arbitrators described in the previous section, reach similar conclusions. In addition, they have data on both conventional and final-offer awards in the same cases that are used to strengthen the conclusion that there is common underlying

9. As long as the weight on the offers relative to the facts is a function of the quality of the offers, the offers are also bounded in CA. One of the themes of this study is that it is not obvious, a priori, which type of arbitration ought to lead to less disagreement. 
notion of an appropriate award that governs arbitrator behavior in both CA and FOA.

VI. The Specification of the Model

To the extent possible the calculations of the identical-expectations contract zones are based on empirical estimates of the relevant behavioral functions. Central to the analysis is the behavior of the arbitrators, and we rely on estimates of the models of arbitrator behavior in CA and FOA derived by Farber and Bazerman (1986). This is a particularly convenient choice because the hypothetical cases that their arbitrators decide can be integrated into a general model of negotiator behavior very conveniently. In the model of $C A$, the key parameters represent the sensitivity of the arbitration award to changes in the offers. Recall from equation (4.1) that the arbitration award is a weighted average of the arbitrator's notion of an appropriate award $\left(Y_{e}\right)$ and the average of the offers $(\bar{Y})$. The key idea is that the weight depends on the quality of the offers so that the weight the arbitrator puts on $Y_{e}$ is inversely related to the quality of the offers. The function used by Farber and Bazerman is

$$
\text { (6.1) } \gamma=\gamma_{0}+\gamma_{1}\left[Y_{u}-Y_{m}\right]
$$

where $Y_{u}$ and $Y_{m}$ are the offers of the union and management respectively. The parameter $\gamma_{1}$ is positive reflecting the notion that the weight on the offers $(1-\gamma)$ is relatively low where the parties are far from agreement.

Bazerman and Farber derive surprisingly large estimates for $\gamma$ at the observed differences in offers which suggests that the arbitrator puts most of the weight on the facts exclusive of the offers. A summary of Bazerman and Farber's estimates is 


$$
\begin{aligned}
(6.2) \times= & .741+1.53\left[Y_{\mathrm{u}}-\mathrm{Y}_{\mathrm{m}}\right] \\
& (.0504)(.603)
\end{aligned}
$$

where the numbers in parenthesis are asymptotic standard errors. The range of difference between the offers in the hypothetical cases was from approximately .01 ( 1 percentage point in the wage increase) to .12 (12 percentage points in the wage increase). Clearly, the smallest predicted value of $\gamma$ is .74 (se=.05) so that even where the parties are very close to agreement three quarters of the weight is on the facts. At the largest sample values of $\mathrm{Y}_{\mathrm{u}^{-}}$ $\mathrm{Y}_{\mathrm{m}}$, the predicted value of $\gamma$ is approximately .93 (se=.03). Thus, the marginal effect of a change in the offers on the weights is relatively small. Given the much smaller value for $\gamma$ implicit in the recent study by Bloom (1986), the identical-expectations contract zones will also be computed using lover values for $\gamma_{0}$ for comparison. While Bloom's work does not address the issue of the sensitivity of the weights to the quality of the offers, identical-expectations contract zones will also be computed using a variety of values of $\gamma_{1}$ in order to investigate the how sensitive the identicalexpectations contract zone is to this parameter.

The other parameter of interest from the Farber and Bazerman estimation is the variance of $\mathrm{Y}_{\mathrm{e}}$ to the extent that this is a plausible estimate of the parties' uncertainty regarding $Y_{e}$. They specify the function determining $Y_{e}$ as

$$
\text { (6.3) } Y_{e}=X \theta+\varepsilon
$$

where $\mathrm{X}$ is a vector of observable characteristics of each case, $\beta$ is a vector of parameters, and $\varepsilon$ is a random component. Assuming that $B$ and $X$ are known ex ante, the relevant variance is the variance of $\varepsilon$. Farber and Bazerman's estimate of this variance is $.000449(\mathrm{se}=.0000228) .10$

10. Farber and Bazerman also estimate the variance of an additive error implicit in equation (4.1) determining the actual award. This variance is 
In FOA, the arbitrator is assumed to seject the offer that is closest to $Y_{e} \cdot$ Clearly, the weighting function $(\gamma)$ is not relevant. However, the variance of $Y_{e}$ is central, and the estimate of the variance of $\varepsilon$ derived by Farber and Bazerman for FOA is .000344 (se=.0000243). This is very close to the variance of $E$ in the $C A$ case although the hypothesis that the variances are equal can be rejected at conventional levels of significance ${ }^{11}$ We proceed using a common value of .0004 for the variance of $\mathrm{y}_{e}$ although identicalexpectations contract zones are also calculated for a range of other values for comparison purposes.

Bazerman (1985) finds that arbitrators differ substantially in the weights they place on the various factors that determine $y_{e}$. In other words, - differs across arbitrators. The parties are likely to be uncertain about what arbitrator they will get, yielding a prior distribution on $B$. In this case, assuming independence of $\beta$ and $\varepsilon, \operatorname{VAR}\left(Y_{e}\right)=X[\operatorname{VAR}(\beta)] X^{\prime}+\operatorname{VAR}(\varepsilon)$ which is certainly larger than $\operatorname{VAR}(\varepsilon)$. Given that the uncertainty regarding the identity of the arbitrator is revealed before the arbitration award, the uncertainty about $Y_{e}$ is reduced at this stage. In some cases the parties might bargain to this stage in order to see if they get a "good" arbitrator, and once this uncertainty is resolved they would settle. This could explain why settlements occur between the point in the process when the arbitrator is appointed and when the arbitration hearing takes place. ${ }^{12}$ Given the difficulty of incorporating this feature of the process into the computations

much smaller: $.0000114(\mathrm{se}=.00000395)$. We ignore this source of randomness here here.

11. The differences in variances is $1.05 \times 10-4$ while the standard error of the difference is $.384 \times 10-4$. Note that the conventional and final-offer decisions were analyzed jointly so that there is a covariance between the estimated variances that was taken into account in computing the variance of the difference. See Farber and Bazerman (1986).

12. Bloom and Cavanagh (1986) present an interesting analysis of the arbitration selection mechanism that has implications for this discussion. 
and the fact that uncertainty regarding the identity of the arbitrator is often revealed before the last offers are finalized, this source of uncertainty does not play a direct role in our calculations.

The central aspect of both union and employer preferences that is relevant for the determination of the identical-expectations contract zone is attitude toward risk. While there is an extensive empirical literature on union utility functions, there is little evidence that bears directly on the degree of risk aversion. ${ }^{13}$ similarly, most of the literature on firm behavior assumes risk neutrality, but this is not evidence on attitude toward risk.

The analysis proceeds by assuming that the parties have constant absolute risk aversion utility functions defined over wages that are symmetrical in form. The union's utility function is

$$
\text { (6.4) } U_{u}(Y)=1-\exp \left[-\delta_{u}\left(Y-Y_{1}\right)\right]
$$

where $\delta_{u}$ is the union's coefficient of absolute risk aversion and $Y_{1}$ represents a minimum value of $Y$ that serves as a benchmark to the union. Similarly, the employer's utility function is

$$
\text { (6.5) } U_{m}(Y)=1-\exp \left[-\delta_{m}\left(Y_{h}-Y\right)\right]
$$

where $\delta_{\mathrm{m}}$ is the employer's coefficient of absolute risk aversion and $\mathrm{Y}_{h}$ represents a maximum value of $Y$ that serves as a benchmark to the employer. The union's utility is increasing in $Y$ while the employer's utility is decreasing in $Y$. Without an empirical guide to appropriate values for $\delta_{u}$ and

13. Farber (1978), Dertouzos and Pencavel (1980), Carruth and Oswald (1983), Pencavel (1984), Brown and Ashenfelter (1986), and MaCurdy and Pencavel (1986) all present studies of union behavior based on utility maximization. Only Farber (1978) presents an explicit estimate of the union's risk aversion. However, his estimate is based on the tradeoff between wages and employment in determining wages, and this is not really the sort of risk considered here. Farber (1986) presents a survey of this literature. See Tversky and Kahneman (1974) and Bazerman (1986) for more general behavioral discussions of decision making under uncertainty. 
${ }^{\delta}$ ' identical-expestations contract zones are computed for a wide variety of values of $\delta_{u}$ and $\delta_{\mathrm{m}}$ ranging from 5 to $100 .^{14}$

It is assumed that the parties' prior distribution on $\mathrm{Y}_{\mathrm{e}}$ is normal with mean . 1 (think of this as an average 10 percent wage increase) and variance .0004 . The particular value selected for the mean is not crucial, and the qualitative nature of the findings will not be affected by a different choice of mean. The crucial assumption regarding the mean is that both parties's beliefs about $Y_{e}$ are identical. On the the basis of this assumption and the definition of $Y_{S}$ in equation (4.1), the actual $C A$ award is also distributed normally (conditional on the offers) with mean

(6.6) $\left.E\left(Y_{S}\right)=\gamma E\left(Y_{e}\right)+(1-\gamma) \bar{Y}\right)$

and variance

(6.7) $\operatorname{Var}\left(Y_{s}\right)=\gamma^{2} \operatorname{Var}\left(Y_{e}\right)$.

Given that $\gamma=\gamma_{0}+\gamma_{1}\left(Y_{u}-Y_{m}\right)$, it is clear that both the mean and variance of the distribution of actual awards are functions of the offers.

The expected utility of the union in $C A$ is

$$
\text { (6.8) } \quad E\left(U_{u}\right)=\int U_{u}\left(Y_{s}\right) f\left(Y_{s}\right) d Y_{s^{\prime}}
$$

where $f_{\left(Y_{S}\right)}$ is the appropriate normal density function. Similarly, the employer's expected utility in $C A$ is

$$
\text { (6.9) } E\left(U_{m}\right)=\int U_{m}\left(Y_{s}\right) f\left(Y_{s}\right) d Y_{s} \text {. }
$$

Both of these expected utilities are functions of the offers because $Y_{s}$ is fundamentally affected by the offers both directly and through the $r$ function. The direct effect of an increase in the union's offer or a decrease in the employer's offer on the arbitration award is offset by a reduction in the weight placed on the offers. This is the tradeoff faced by the parties in

14. Given an average value of $Y$ of .1, this range of absolute risk aversions translates into a range of relative risk aversions of .5 to 10 . 
selecting their offers. If each party can manipulate its last offer so as to maximize its own expected utility, a natural equilibrium concept is the Nash Equilibrium. This is the pair of offers that has the property that neither party can increase its expected utility by changing its offer.

Given the Nash equilibrium offers, it is straightforward to derive the certainty equivalent outcomes that determine the limits of the identicalexpectations contract zone as described in section III. If at least one party is risk averse $\left(\delta_{u}>0\right.$ or $\left.\delta_{m}>0\right)$ and neither party is risk seeking $\left(\delta_{u} 20\right.$ and $\delta \mathrm{m}^{201}$, it is true that this identical-expectations contract zone will be of positive length.

In FOA, the arbitrator is constrained to select one or the other of the parties' final offers. In this case the arbitrator is assumed to select the offer that is closest to $Y_{e}$. Given the assumption of a normal distribution for $Y_{e}$ described above, the probability of choosing the employer's offer is

$$
\text { (6.10) } \mathrm{P}_{\mathrm{m}}=\operatorname{Pr}\left(\mathrm{Y}_{\mathrm{e}}\langle\overline{\mathrm{Y}})=\mathrm{F}(\overline{\mathrm{Y}})\right.
$$

where $F(\cdot)$ represents the normal cumulative distribution function of $Y_{e}$ with appropriate mean and variance. The union's expected utility from arbitration in this case is

$$
\text { (6.11) } E\left(U_{u}\right)=P_{m} U_{u}\left(Y_{m}\right)+\left[1-P_{m}\right] U_{u}\left(Y_{u}\right)
$$

while the employer's expected utility from arbitration is

$$
\text { (6.12) } E\left(U_{m}\right)=P_{m} U_{m}\left(Y_{m}\right)+\left[1-P_{m}\right] U_{m}\left(Y_{u}\right) \text {. }
$$

Note that an increase in the union's offer increases its payoff if its offer is selected, but it reduces the probability that its offer is, in fact, selected. Similarly, a decrease in the management's offer increases its payoff if its offer is selected, but it reduces the probability that its offer is, in fact, selected. This is the fundamental tradeof the parties face in selecting their optimal offers in FOA. The Nash equilibrium pair of offers, are derived as above. These offers are used to compute the levels of expected 
utilities that define the certainty equivalent outcomes, $Y_{c u}$ and $Y_{c m}$ ' that are the limits of the identical-expectations contract zone. Once again, as long as at least one party is risk averse and neither party is risk seeking, it will be true that $\mathrm{Y}_{\mathrm{Cu}}\left\langle\mathrm{Y}_{\mathrm{cm}}\right.$ so that there exists a positive identicalexpectations contract zone.

Denote the size of the identical-expectations contract zone under $C A$ and FOA by $\mathrm{CZ}_{c}$ and $\mathrm{CZ}_{f}$ respectively. The analysis consists of computing values of $\mathrm{CZ} Z_{c}$ and $\mathrm{CZ} Z_{f}$ using the assumed specification of union and employer preferences described above combined with the specification of arbitrator behavior based on Farber and Bazerman's (1986) explicitly estimated model of arbitrator behavior. These identical-expectations contract zones are computed for a range of values of union and employer risk aversions, levels of uncertainty about $\mathrm{Y}_{\mathrm{e}^{\prime}}$ and parameters of the arbitrator's weighting function ( $\gamma$ ) in CA.

\section{Estimates of Identical-Expectations Contract Zone Size}

Table 1 contains estimates of identical-expectations contract zone size in $C A$ and FOA for a range of levels of risk aversions and variance of $Y_{e}$. All of these values are computed at the point estimates of $\gamma_{0}$ and $\gamma_{1}$ presented in the last section and derived from Farber and Bazerman (1986). The results are quite striking. Except at the lowest levels of risk aversion, where $\mathrm{Cz}_{c}$ and $\mathrm{CZ}_{\mathrm{f}}$ are virtually indistinguishable, the identical-expectations contract zones in $\mathrm{CA}$ are uniformly larger than the identical-expectations contract zones in FOA. As expected, the identical-expectations contract zones increase in size with the variance of $\mathrm{Y}_{\mathrm{e}}$, but the finding of larger identical-expectations contract zones in CA persists. In addition, the differences are not small. For example, the identical-expectations contract zone is fully two and one half times larger in CA for the intermediate case where $\delta_{u}=\delta_{\mathrm{m}}=50$ and 
Table 1.

Contract Zones for Various Levels of Risk Aversion and Variance of $\mathrm{Y}_{e}$.

\begin{tabular}{|c|c|c|c|c|c|c|c|c|c|c|}
\hline \multirow{3}{*}{$\delta_{u}$} & \multirow{2}{*}{$\delta_{\mathrm{m}}$} & \multirow{2}{*}{1} & \multicolumn{2}{|c|}{$\operatorname{Var}=.0002$} & \multicolumn{2}{|c|}{ Var $=.0004$} & \multicolumn{2}{|c|}{$\operatorname{Var}=.0006$} & \multicolumn{2}{|c|}{ Var $=.002$} \\
\hline & & & FOA & CONV & FOA & CONV & FOA & CONV & FOA & CONV \\
\hline & & 1 & & & & & & & & \\
\hline$=5$ & 5 & $\begin{array}{l}1 \\
1\end{array}$ & .0013 & .0010 & .0025 & .0020 & .0036 & .0029 & .0098 & .0094 \\
\hline 20 & 5 & $\begin{array}{l}1 \\
1\end{array}$ & .0027 & .0025 & .0047 & .0049 & .0064 & .0072 & .0149 & .0216 \\
\hline 20 & 20 & 1 & .0036 & .0039 & .0059 & .0076 & .0078 & .0112 & .0164 & .0318 \\
\hline 50 & 5 & $\begin{array}{l}1 \\
1\end{array}$ & .0041 & .0053 & .0066 & .0103 & .0085 & .0150 & .0163 & .0403 \\
\hline 50 & 20 & $\begin{array}{l}1 \\
1\end{array}$ & .0045 & .0067 & .0070 & .0129 & .0089 & .0185 & .0163 & .0474 \\
\hline 50 & 50 & $\begin{array}{l}1 \\
1\end{array}$ & .0050 & .0094 & .0074 & .0178 & .0091 & .0251 & .0157 & .0586 \\
\hline 100 & 5 & 1 & .0050 & .0099 & .0073 & .0185 & .0089 & .0262 & .0141 & .0601 \\
\hline 100 & 20 & 1 & .0051 & .0112 & .0074 & .0208 & .0089 & .0292 & .0142 & .0642 \\
\hline 100 & 50 & $\begin{array}{l}1 \\
1\end{array}$ & .0052 & .0137 & .0074 & .0252 & .0089 & .0384 & .0138 & .0705 \\
\hline 100 & 100 & 1 & .0053 & .0178 & .0072 & .0318 & .0084 & .0429 & .0127 & .0770 \\
\hline
\end{tabular}

All estimates assume $\gamma=.741+1.53\left(Y_{\mathrm{u}}-\mathrm{Y}_{\mathrm{m}}\right)$. 
Var=.0004. In absclute terns, the ilentical-exjectations contract zone in $\mathrm{Ch}$ is approximately 2.5 percentage points of wage increase while it is only 0.9 percentage points of wage increase in FOA.

It is possible that the finding that the identical-expectations contract zone is larger in CA than in FOA is quite sensitive to the particular values selected for $\gamma_{0}$ and $\gamma_{1}$. In order to investigate this more fully, table 2 contains estimates of identical-expectations contract zone size in CA and FOA for a range of values of $\gamma_{0}$ and $\gamma_{1}$. All of these values are computed assuming that $\operatorname{Var}\left(Y_{e}\right)=.0004$, and the estimates of the identical-expectations contract zones in FOA, contained in the first column of table 2, are not affected by the choice of $\gamma$.

The second column of table 2 contains estimates of the identicalexpectations contract zone in $\mathrm{CA}$ for the actual point estimates derived by Farber and Bazerman (1986) $\left(\gamma_{0}=.741, \gamma_{1}=1.53\right)$. The third column contains the estimates for a model meant to reflect Bloom's (1986) conclusion that splitting-the-difference is a good description of arbitrator behavior. In this case, $\gamma_{1}$ is unchanged while $\gamma_{0}$ is reduced to 0.25 so that the weight on $\mathrm{Y}_{\mathrm{e}}$ is small where the offers are close together. The identical-expectations contract zones are not at all affected by a shift in $\gamma_{0}$ holding the other parameters fixed. In more formal terms, it can be shown that the equilibrium value of the identical-expectations contract zone in CA is

$$
\text { (7.1 } \quad C z_{c}=\gamma^{2} \sigma^{2}\left(\delta_{u}+\delta_{m}\right) / 2
$$

which depends solely on the parameters of the utility functions, the parameters of the prior distribution on $Y_{e^{\prime}}$ and the equilibrium value of $\gamma$. The latter is

$$
\text { (7.2) } \quad \gamma=1 /\left[1+\left(\delta_{\mathrm{u}}+\delta_{\mathrm{m}}\right) \gamma_{1} \sigma^{2}\right]
$$

which depends only on the parameters of the utility functions, the parameters of the prior distribution on $Y_{e}$, and the parameter $\gamma_{1}$. It does not depend on 
Table 2

Contract Zones under Alternative Assumptions about Arbitrator $\left(\gamma=\gamma_{0}+\check{o}_{1}\left[Y_{u}-Y_{m}\right]\right)$

\begin{tabular}{|c|c|c|c|c|c|c|c|}
\hline \multirow[b]{2}{*}{$\delta_{\mathrm{u}}$} & \multirow[b]{2}{*}{$\delta_{\mathrm{m}}$} & 1 & \multirow{2}{*}{ Final offer } & \multicolumn{3}{|c|}{ Conventional } & \multirow[b]{2}{*}{$\begin{array}{l}\gamma_{0}=.741 \\
\gamma_{1}=5.0\end{array}$} \\
\hline & & $\begin{array}{l}1 \\
1 \\
1 \\
1\end{array}$ & & $\begin{array}{l}\gamma_{0}=.741 \\
\gamma_{1}=1.53\end{array}$ & $\begin{array}{l}\gamma_{0}=.25 \\
\gamma_{1}=1.53\end{array}$ & $\begin{array}{l}\gamma_{0}=.741 \\
\gamma_{1}=.50\end{array}$ & \\
\hline & & 1 & & & & & \\
\hline 5 & 5 & $\begin{array}{l}1 \\
1\end{array}$ & .0025 & .0020 & .0020 & .0020 & .0019 \\
\hline 20 & 5 & $\begin{array}{l}1 \\
1\end{array}$ & .0047 & .0049 & .0049 & .0050 & .0045 \\
\hline 20 & 20 & $\begin{array}{l}1 \\
1\end{array}$ & .0059 & .0076 & .0076 & .0079 & .0069 \\
\hline 50 & 5 & $\begin{array}{l}1 \\
1\end{array}$ & .0066 & .0103 & .0103 & .0108 & .0089 \\
\hline 50 & 20 & $\begin{array}{l}1 \\
1\end{array}$ & .0070 & .0129 & .0129 & .0136 & .0108 \\
\hline 50 & 50 & $\begin{array}{l}1 \\
1\end{array}$ & .0074 & .0178 & .0178 & .0192 & .0139 \\
\hline 100 & 5 & 1 & .0073 & .0185 & .0185 & .0201 & .0143 \\
\hline 100 & 20 & 1 & .0074 & .0208 & .0208 & .0229 & .0156 \\
\hline 100 & 50 & $\begin{array}{l}1 \\
1\end{array}$ & .0074 & .0252 & .0252 & .0283 & .0178 \\
\hline 100 & 100 & 1 & .0072 & .0318 & .0318 & .0370 & .0204 \\
\hline
\end{tabular}

All estimates assume variance of $\mathrm{Y}_{\mathrm{e}}=.0004$. 
$\mathrm{C}_{0}$ i5 This extreme result is certainly an artifact of the linear specification for $\gamma$. However, it is likely to approximate the findings from more general specifications.

The third column of table 2 contains estimates of the identicalexpectations contract zone in CA for the case where the weights are less sensitive to the offers $\left(\gamma_{1}=0.5\right)$. In this case, the identical-expectations contract zone is even larger than in the base case $\left(\gamma_{1}=1.53\right)$. Intuitively, the parties face an even worse tradeof in attempting to reduce the risk by shifting the weight away from $Y_{e}$. The last column of table 2 contains estimates of the identical-expectations contract zone in CA for the case where the weights are very sensitive to the offers $\left(\gamma_{1}=5.0\right)$. In this case the identical-expectations contract zones in $\mathrm{CA}$ are smaller than in the base case, but they are still larger than in FOA.

Overall, the finding that identical-expectations contract zones are larger in CA than in FOA seems robust to fairly large changes in the parameters of the model. ${ }^{16}$ The immediate interpretation of this result is that the divergent expectations model of disagreement is not what is driving the higher rate of disagreement in CA relative to FOA.

\section{Alternative Explanations for Disagreement}

The evidence presented in this paper clearly suggests that the divergent expectations argument does not fully explain the disagreements that occur in

15. For the equilibrium value of $\gamma$ to be independent of $\gamma$ it must be the case that where $\gamma_{0}$ is lower the equilibrium offers must be further apart in order to compensate (increase the value of $\gamma$ ). This is confirmed in table 4. However, the uncertainty regarding the arbitration award comes solely from $\gamma \mathrm{Y}$.
so that the contract zone is unchanged as long as $\gamma$ is unchanged.

16. Of course, the findings may not be robust to changes in the functional forms of the utility functions or the prior distribution on $Y_{e}$. 
the labor-management negotiations. In fact, the identical-expectations contract zones are in direct contrast to the predictions of the divergent expectations argument. Other explanations of disagreement are necessary. We propose four alternatives based on an analysis of economic, structural, and cognitive features of the negotiation process. For each explanation, we evaluate the degree to which the predictions of that explanation are consistent with our evidence.

One class of models that has been suggested recently as an equilibrium explanation for disagreements in bargaining is based on the idea that there is asymmetric information held by party 1 that party 2 attempts to learn about by making offers that party 1 is free to accept or reject (.e.g. Fudenberg and Tirole, 1981; Sobel and Takahashi, 1983; and Tracy, 1986). The most common form of the argument (very simplified here) is that firms have private information about their profitability that they cannot credibly transmit to the union. In a two period model, the union formulates a first-period demand that the firm will accept if it is high profit (resulting in agreement) and reject if it is low profit (resulting in disagreement). This strategy is optimal from the union's point of view since it would like a high wage if possible. The firm can only make credible the fact that it is low profit by incurring the cost of disagreement. Hence, there will be disagreement some of the time. This theory has the clear implication (Tracy, 1986) that there will be less disagreement where the total costs of disagreement are higher.

Given that identical-expectations contract zone size is an indicator of total costs of disagreement, this simple theory predicts that there would be less disagreement where the identical-expectations contract zone is smaller. This is not consistent with the basic evidence that identical-expectations contract zones are larger and there is more disagreement in CA than in FOA. This suggests that learning in at least such simple models of asymmetric 
iaformation is not a sufficient explanation of disagreement.

Another recent alternative classs of models of disagreement has been developed by Crawford (1982) and is based on Schelling's (1956) model of commitment. The basic idea is that it may be advantageous in bargaining for the parties to commit to a position that would be very costly to disavow. Crawford (1982) develops a model where the potential for commitment by both parties can lead to disagreement as long as there is an element of irreversibility in the commitment and there is uncertainty about the strength of the parties' commitments. A sketch of the model is that commitment is reversible only at some uncertain cost and neither party knows this cost ex ante. In the first stage of bargaining in this model the parties determine whether they will attempt commitment. In the second stage, the cost of backing down is revealed to each party but not to the other party. At this point each party determines if they should back down, not knowing for certain whether the other party will back down.

Three classes of outcomes are possible. If both parties commit, there is disagreement. If only one party commits, that party gets a favorable settlement. Finally, if neither party commits, there is some solution concept that leads to agreement. The key is that there is a nonzero probability that both parties commit successully, resulting in disagreement. Anything that increases the payoff to commitment will increase the probability of successful commitment and, hence, the probability of disagreement. Where the contract zone is large, a successful commitment may or may not have a larger payoff. Crawford argues that there is no clear prediction of the model regarding the extent to which the size of the contract zone affects the likelihood of commitment. However, he concludes that the concitions on the model required to predict unambiguously that larger contract zones lead to less commitment (and hence less disagreement) are not likely to be satisfied. 
With regard to the evidence, this commitment theory has no implications for the relationship between contract zone size and the likelihood of agreement. Indeed, it is difficult to think of what evidence could be used to test this theory. Thus, while the commitment theory does not contradict the evidence, this is simply because of a lack of a clear prediction. The theory does not predict the strong pattern of evidence.

The third alternative explanation of disagreement concerns the structural feature of the arbitration process that arbitrators often receive information from the parties in hearings regarcing the course of negotiations. In this context, it will be difficult for the parties to "retrench" from concessions made in bargaining in order to present the optimal offers to the arbitrators. For example, if the union's optimal offer for the arbitrator is a 10 percent wage increase but it's certainty equivalent is 6 percent (the least it will accept in bargaining), the union may be reluctant to concede much below ten percent if it is uncertain about reaching agreement for fear an offer to settle of, say, 8 percent will be used against it in the hearing with the arbitrator. ${ }^{17}$ It is reasonable to argue that where the equilibrium offers to be presented to the arbitrator are farther apart, the parties will be more reluctant to concede in bargaining. In addition, where the parties are far apart, perhaps because of a reluctance to concede, they are likely to be less certain that a negotiated settlement is possible. Where the optimal offers are closer together, the parties will more Iikely be able to concede to a

17. In the civil-court system, which is perfectly analogous to labor arbitration (out-of-court settlement = negotiated settlement, trial outcome = arbitration award), offers to settle out of court are not admissible as evidence in a trial. This is precisely to avoid a reluctance to concede in attempts to reach a negotiated settlement. Wheeler (1977) suggests that arbitration procedures be modified to more closely reflect the civil-court system by having the record of the negotiations not admissible. He calls his procedure closed-offer arbitration. 
point where agreement looks more certain, encouraging further concession and. eventual agreement.

With regard to the evidence presented above, the higher settlement rates in FOA are consistent with this argument if the optimal offers in FOA are closer together than the optimal offers in CA. Table 3 contains calculations of the differences in the final offers for the values of union and employer risk aversion and the level of uncertainty regarding $Y_{e}$ used in the previous section. In every case, the offers are much farther apart in CA than in FOA (in the intermediate case $\left(\delta_{u}=\delta_{\mathrm{m}}=50\right.$, var $\left.=.0004\right)$ by a factor of 5$)$. Table 4 contains estimates of the difference in the offers for various values of the parameters of the CA weighting function. Except for the case (column 5) where the weight is extremely sensitive to the difference in the offers $\left(x_{1}=5.0\right)$, it is true that the offers are much further apart in CA than FOA. In the middle risk aversion case $\left(\delta_{\mathrm{u}}=\delta_{\mathrm{m}}=50\right)$ approximating Bloom's estimates of the weighting function $\left(\gamma_{0}=.25, \gamma_{1}=1.53\right)$, the difference in offers in CA is fully 18 times larger than the difference in the offers in FOA (.453 versus .0251$)$. Intuitively, where the marginal effect of a change in the offers on $\gamma$ is small (column 3), the equilibrium offers in CA will be far apart. Where the marginal effect is large, the equilibrium offers will be close together (column 4).

The evidence is clearly consistent with the hypothesis that the higher settlement rate in FOA is due to the convergence of the optimal offers in FOA combined with the structural features of the arbitration process that make it difficult to retrench to the optimal offers once concessions beyond that point have been made.

The final potential explanation of disagreement is based on the notion that the effect of the offers on the arbitration award is much more salient to the parties in FOA than in CA. That this is possible is obvious from the 
Table 3 .

Offer Differences for Various Levels of Risk Aversion and Variance of $Y_{e}$

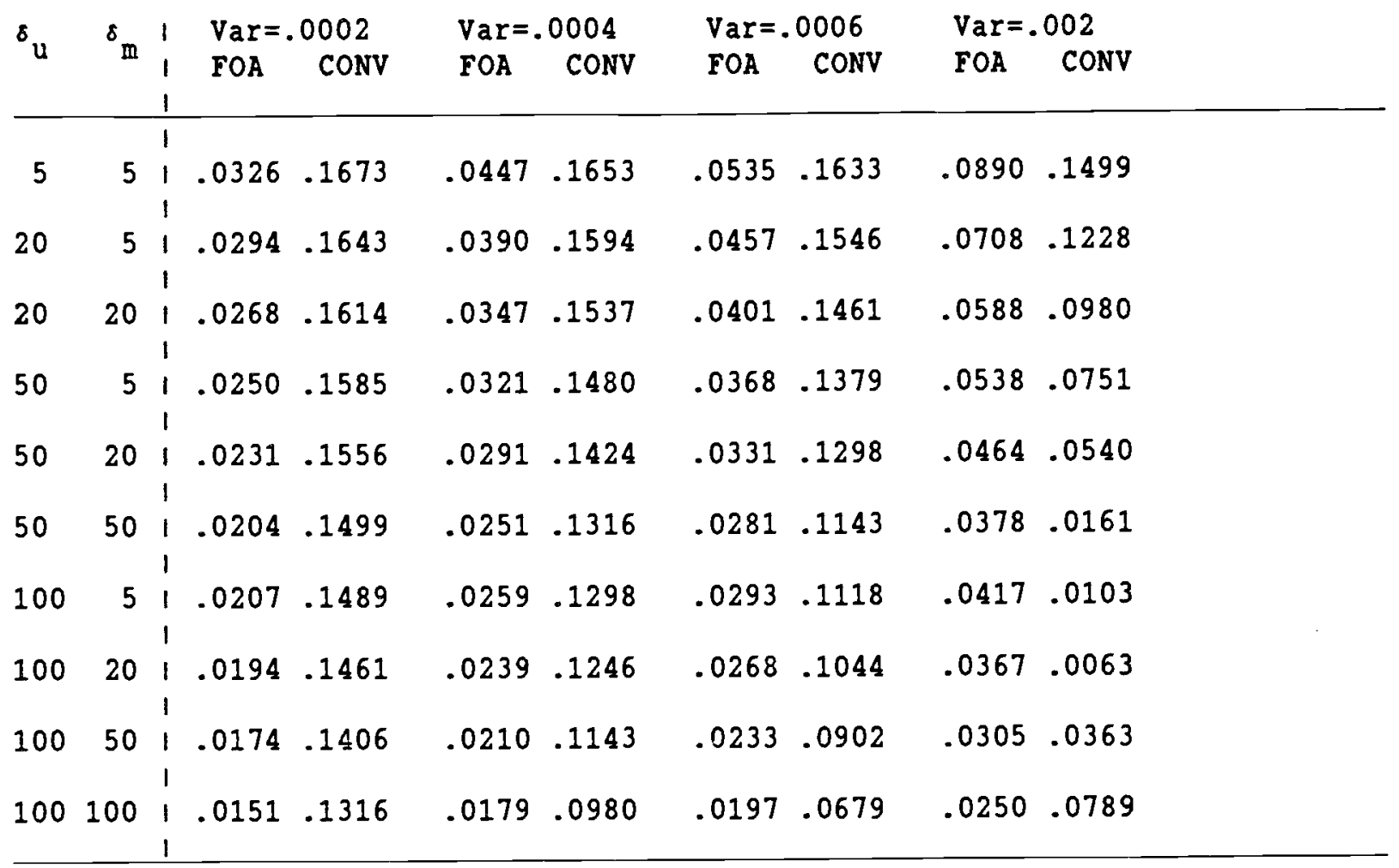

All estimates assume $\gamma=.741+1.53\left(Y_{\mathrm{u}}-\mathrm{Y}_{\mathrm{m}}\right)$. 
Table 4

Offer Differences under Alternative Assumptions about Arbitrator $\left(\gamma=\gamma_{0}+\gamma_{1}\left[Y_{u}-Y_{m}\right]\right)$

\begin{tabular}{|c|c|c|c|c|c|c|c|}
\hline \multirow[b]{2}{*}{${ }^{\delta} \mathrm{u}$} & \multirow[b]{2}{*}{$\delta_{m}$} & 1 & Final offer & \multicolumn{3}{|c|}{ Conventional } & \multirow[b]{2}{*}{$\begin{array}{l}\gamma_{0}=.741 \\
\gamma_{1}=5.0\end{array}$} \\
\hline & & $\begin{array}{l}1 \\
1 \\
1 \\
1\end{array}$ & & $\begin{array}{l}\gamma_{0}=.741 \\
\gamma_{1}=1.53\end{array}$ & $\begin{array}{l}\gamma_{0}=.25 \\
\gamma_{1}=1.53\end{array}$ & $\begin{array}{l}\gamma_{0}=.741 \\
\gamma_{1}=.50\end{array}$ & \\
\hline 5 & 5 & $\begin{array}{l}1 \\
1 \\
1\end{array}$ & .0447 & .1653 & .486 & .514 & .0478 \\
\hline 20 & 5 & $\begin{array}{l}1 \\
1\end{array}$ & .0390 & .1594 & .480 & .508 & .0423 \\
\hline 20 & 20 & $\begin{array}{l}1 \\
1\end{array}$ & .0347 & .1537 & .475 & .502 & .0370 \\
\hline 50 & 5 & $\begin{array}{l}1 \\
1\end{array}$ & .0321 & .1480 & .469 & .496 & .0320 \\
\hline 50 & 20 & $\begin{array}{l}1 \\
1\end{array}$ & .0291 & .1424 & .463 & .490 & .0272 \\
\hline 50 & 50 & $\begin{array}{l}1 \\
1\end{array}$ & .0251 & .1316 & .453 & .479 & .0184 \\
\hline 100 & 5 & $\begin{array}{l}1 \\
1\end{array}$ & .0259 & .1298 & .451 & .477 & .0170 \\
\hline 100 & 20 & $\begin{array}{l}1 \\
1\end{array}$ & .0239 & .1246 & .445 & .471 & .0131 \\
\hline 100 & 50 & 1 & .0210 & .1143 & .435 & .460 & .0056 \\
\hline 100 & 100 & $\begin{array}{l}1 \\
1\end{array}$ & .0179 & .0980 & .419 & .441 & .0000 \\
\hline
\end{tabular}

All estimates assume variance of $\mathrm{Y}_{\mathrm{e}}=.0004$. 
structures of the iwo procedures. ${ }^{18}$ In FOA there is no escaping consideration of the direct effect that a party's offer will have on the arbitration award. In $C A$, the parties could well ignore the effects that their offers have on the awards and maintain extreme positions. In essence, this argument has as its base that the parties do not calculate the optimal offers the way that was outlined above in $C A$. In FOA they may do something closer to what was outlined for that procedure because FOA is structured in a way that highlights the relevant tradeoffs. In the context of negotiation, there is evidence from the laboratory (Bazerman and Carroll, 1987) that negotiators are generally not very good at working out the structure of the game they are playing or considering the perspective of opponents and third parties. At the same time there is laboratory evidence (Bazerman and Neale, 1982; Neale and Bazerman, 1983) that FOA encourages more concessionary behavior than CA precisely because its structure encourages each party to take the perspective of the other party, a trait that they show leads to more agreement.

Overall, the evidence presented in this study (higher settlement rates in FOA relative to $C A$, larger identical-expectations contract zones in $C A$, and more disperse offers in $C A$ ) casts some doubt that a divergence of expectations regarding the disagreement outcome is the primary cause of failure to reach a negotiated settlement. The evidence also is not consistent with the view that labor disputes are due to optimal learning by one party in a situation where there is private information held by one party that can be extracted through a labor dispute. The model of disagreement as the result of commitment strategies considered here has no clear implications for our evidence so that

18. It is also obvious from the presentations in sections IV and $V$ of arbitrator behavior in $C A$ and $F O A$ respectively. The discussion of $C A$ is long and involved while the discussion of FOA is relatively concise. 
it cannot be evaiuated here. A pair of alternatives that are consistent with the evidence are presented including 1) a reluctance to concede where the optimal offers for the arbitrator are far apart in fear that concessions could "come back to haunt them" in arbitration and 2) a lack of salience of the role of the offers leading to a failure to take the opponents perspective in CA. 


\section{References}

Ashenfelter, O. and David E. Bloom "Models of Arbitrator Behavior: Theory and Evidence," American Economic Review 74 (March 1984): 111-124.

Ashenfelter, Orley and James N. Brown. "Testing the Efficiency of Employment Contracts," Journal of Political Economy 94 (June 1986): S40-S87.

Bazerman, Max H. "Norms of Distributive Justice in Interest Arbitration," Industrial and Labor Relations Review, 39 (July 1985): 558-570.

Bazerman, Max H. Judgement in Management Decision Making, New York: Wiley, 1986.

Bazerman, Max H. and John S. Carroll. "Negotiator Cognition," in Research in Organizational Behavior IX, B. M. Staw and L. L. Cummings, eds. JAI Press, 1987 (forthcoming).

Bazerman, Max H. and Henry S. Farber. "Arbitrator Decision Making: When are Final offers Important?" Industrial and Labor Relations Review, 40 (October 1985): 76-89.

Bazerman, Max H. and Margaret A. Neale. "Improving Effectiveness under FinalOffer Arbitration: The Role of Selection and Training," Journal of Applied Psychology 67 (1982): 1-17.

Bloom, David E. "Empirical Models of Arbitrator Behavior Under Conventional Arbitration," Review of Economics and Statistics (1986): 578-585.

Bloom, David E. and Christopher L. Cavanagh. "An Analysis of the Selection of Arbitrators," American Economic Review 76 (June 1986): 408-422.

Carruth, Alan A. and Andrew J. Oswald. "Miner's Wages in Post-War Britain: An Application of a Model of Trade Union Behavior," University of Kent, mimeo (Decmber 1983).

Crawford, Vincent $P$. "A Theory of Disagreement in Bargaining," Econometrica 50 (May 1982): 607-637.

Dertouzos, James N. and John H. Pencavel. "Wage and Employment Determination Under Trade Unionism: The International Typographical Union," Journal of Political Economy 89 (1980): 1162-81.

Farber, Henry S. "Individual Preferences and Union Wage Determination: The Case of the United Mine Workers," Journal of Political Economy 86 (October 1978): $923-42$. (b)

Farber, Henry S. "An Analysis of Final-offer Arbitration," Journal of Conflict Resolution (December 1980). (a)

Farber, Henry S. "Does Final-Offer Arbitration Encourage Bargaining?" Proceedings of the Thirty-third Annual Meeting of the Industrial Relations Research Association, Denver, September 1980. pp. 219-226. (b) 
Farber, Henry S. "Splitting-the-Litference in Interest Arbitration," incustrial and Labor Relations Review 35 (April 1981): 70-77.

Farber, Henry S. "The analysis of Union Behavior," in Handbook of Labor Statistics, 0 . Ashenfelter and R. Layard, eds. North-Holland, 1986. (forthcoming)

Farber, Henry S. and Max H. Bazerman. "The General Basis of Arbitrator Behavior: An Empircal Analysis of Conventional and Final-offer Arbitration," Econometrica 54 (November 1986): 1503-1528.

Farber, Henry S. and Harry C. Katz "Interest Arbitration, Outcomes, and the Incentive to Bargain." Industrial and Labor Relations Review 33 (October 1979): 55-63.

Farber, Henry S., Margaret A. Neale, and Max H. Bazerman. "The Impact of Risk Aversion and Cost of Arbitration on Resolution Rates and Negotiated Outcomes," mimeo, March 1986.

Feuille, Peter. "Final offer Arbitration and the Chilling Effect," Industrial Relations 14 (October 1975): $302-310$.

Freeman, Richard B. "Unionism Comes to the Public Sector," Journal of Economic Literature 24 (March 1986): 41-86.

Fudenberg, Drew and Jean Tirole. "Sequential Bargaining with Incomplete Information," Review of Economic Studies 50 (November 1981): 221-248.

Grigsby, David and William Bigoness. "The Effects of Third Party Intervention on Pre-Intervention Bargaining Behavior," Journal of Applied Psychology 67 (October 1982): 549-54.

Hicks, John. The Theory of Wages, London. MacMillan, 1963.

Kochan, Thomas A. and Jean Baderschneider. "Determinants of Reliance on Impasse Procedures: Police and Firefighters in New York State." Industrial and Labor Relations Review 31 (July 1978): 431-440.

Lewicki, R. J.; Sheppard, B. H.; and M. H. Bazerman. Research in Negotiation in Organizations 1, Greenwich, CT: JAI Press, 1986.

MaCurdy, Thomas E. and John Pencavel. "Testing Between Competing Models of Wage and Employment Determination in Unionized Labor Markets," Journal of Political Economy 94 (June 1986).

Neale, Margaret A. and Max H. Bazerman "The Role of Perspective Taking Ability in Negotiating Under Different Forms of Arbitration," Industrial and Labor Relations Review 36 (April 1983): 378-388.

Notz, W. W. and F.A. Starke "Final offer versus Convnetional Arbitration as Means of Confilct Management," Administrative Science Quarterly 23 (June 1978): 189-203.

Pencavel, John. "The Trade-off Between Wages and Employment in Trade Union Objectives," Quarterly Journal of Economics 99 (1984). 
Pruitt, D. and J. Z. Rubin. Social Conflict: Escalation, Impasse, and Resolution. Reading, MA: Addison-Kesley, 1985.

Raiffa, Howard. The Art and Science of Negotiation. Cambridge, MA: Harvard University Press, 1982.

Schelling, Thomas C. "An Essay on Bargaining," American Economic Review 46 (1956): 281-306.

Sobel, Joel and Ichiro Takahashi. "A Multi-Stage Model of Bargaining," Review of Economic Studies 50 (July 1983): 411-426.

Tracy, Joseph S. "An Emprical Test of an Asymmetric Information Model of Strikes," mimeo, January 1986.

Tversky, Amos and Daniel Kahneman. "Judgement Under Uncertainty: Heuristics and Biases," Science 185 (September 27, 1974): 1124-1131.

United States Bureau of Labor Statistics. Characteristics of Major Collective Bargaining Agreements, January 1, 1980, Bulletin 2095, U.S. Government Printing office, May 1981.

Whe $E$ ler, Hoyt $N$. "Closed Offer: An alternative to Final-offer Selection," Industrial Relations 16 (1977): 298-305. 